\title{
Design against nature
}

Anthony Crabbe, Department of Design, School of Art and Design, Nottingham Trent University, Burton Street, Nottingham NG1 4BU, UK

Preprint of an article published in Design Studies 25 (2004) 415-423

\begin{abstract}
The process of disinfecting pits technology against nature. This issue is considered through examination of the design and development of a microwave disinfecting system for contact lenses. Here, technology intervenes to remedy a naturally occurring deficiency in human sight and the design solution requires indiscriminate annihilation of 'lesser' forms of life. With the march of science transforming our ethical and theological visions, questions are raised about the justifications for this strategy and the senses in which it may be seen to be responsible. The competing discourses of responsibility reveal the attraction of seeking to develop such technologies through multidisciplinary teams.
\end{abstract}

\section{Introduction}

The process of disinfecting pits technology against nature. The technological challenge is to design and produce methods of eradicating populations of potentially infectious microbial life from specific sites in both the human body and habitat. Perhaps the most complex part of the challenge is to disinfect without actually damaging the sites chosen for defence. This explains to some extent the differing levels of disinfection, ranging from pasteurisation (a reduction in the log number of a microbial population) to sterilisation, a total elimination of both cells and spores. There exist an entire range of design approaches to disinfecting, ranging from the formulation of chemical compounds, to the engineering of autoclaves and gamma irradiation chambers. ${ }^{1}$

The present paper presents a case study of the latter kind of approach, the design and development of a microwave disinfecting system for contact lenses. The main purpose in presenting this case study is to reflect upon the chosen design strategy from a broader perspective of design responsibility. In the case of contact lens disinfecting, technology produces an artificial device to remedy a naturally occurring deficiency in human sight.

Yet since the contact device threatens to introduce microbial infections to the eye, health and safety legislation requires the device to be supported by an adjunct lens care product. That product obliges the patient to systematically annihilate 'lesser' forms of life from the lens wearing environment. Viewed in this way, the over-arching question seems to be that of designer 
responsibility, beneath which lie beliefs and values that are seldom compatible. Such issues may appear to be merely peripheral to the design rationale of a disinfecting system, but closer inspection shows that simply to view these matters as contingent is in itself to adopt a particular view of responsibility.

\section{Contact lens regimens}

The most common forms of hard and soft lenses are only suitable to be worn during waking hours. Every evening, the patient is obliged to remove the lenses from the eye and store them in a container before re-inserting them the next morning. This provides opportunity for the patient to actually incubate microbial species in the containers and lenses, and then place the lenses onto a conjunctiva that may be abraded by lens wearing. This could increase the chances for common and otherwise innocuous micro-organisms to cause painful, tenacious, sight threatening diseases such as keratitis.

The industry has always recognised this limitation in daily wear lenses and has invested heavily in developing lens systems that obviate this problem. The two great hopes have been the daily disposable lens and the extended wear lens, which the patient only needs to remove and replace once a month. Both types of lens are in principle suitable for about $70 \%$ of contact lens prescriptions. The daily disposable is predictably, twice as expensive as monthly or annual disposable systems, whereas the efficacy of extended wear lens for ocular health continues to be the subject of clinical debate. ${ }^{2,3}$

Contact lens wearing continues to be a more expensive remedy than spectacle wearing and the cheapest, most widely used format is the daily wear lens. In 1996, a pharmacist and myself became interested in designing a better disinfecting system for daily wear lenses. We believed one answer lay in making it possible for patients to daily irradiate their lenses, solution and storage case in their domestic microwave ovens. In undertaking the kind of design and development that would normally be done by major pharmaceutical companies, out main motivations were to create a lens care system that was both safer and cheaper for patients. We saw that the care industry was dominated by an oligopoly of four transnational corporations, including Nestle' and Ciba Gigy. Along with the UK Monopolies and Mergers Commission, we thought their prices were more justified by their market position than their R\&D costs ${ }^{4}$ and that the disinfecting efficacy of their products could be better. ${ }^{5}$

Microwave treatment offered complete rather than partial kill of all challenge organisms, ${ }^{6}$ it required only a basic saline solution, free of preservatives and additives used to justify relatively high prices, yet associated with allergic reactions. ${ }^{7}$ Furthermore, the most common 'multipurpose' solutions seemed to encourage poor hygiene compliance, with patients ignorant 
of the fact that the disinfecting effect against dangerous species such as Acanthamoeba was negligible if they failed to rub and rinse their lenses thoroughly. ${ }^{8}$ The alternative we designed and developed was a plastic unit for treating lenses in a microwave and a modified solution appropriate for irradiation treatment (Figure 1).

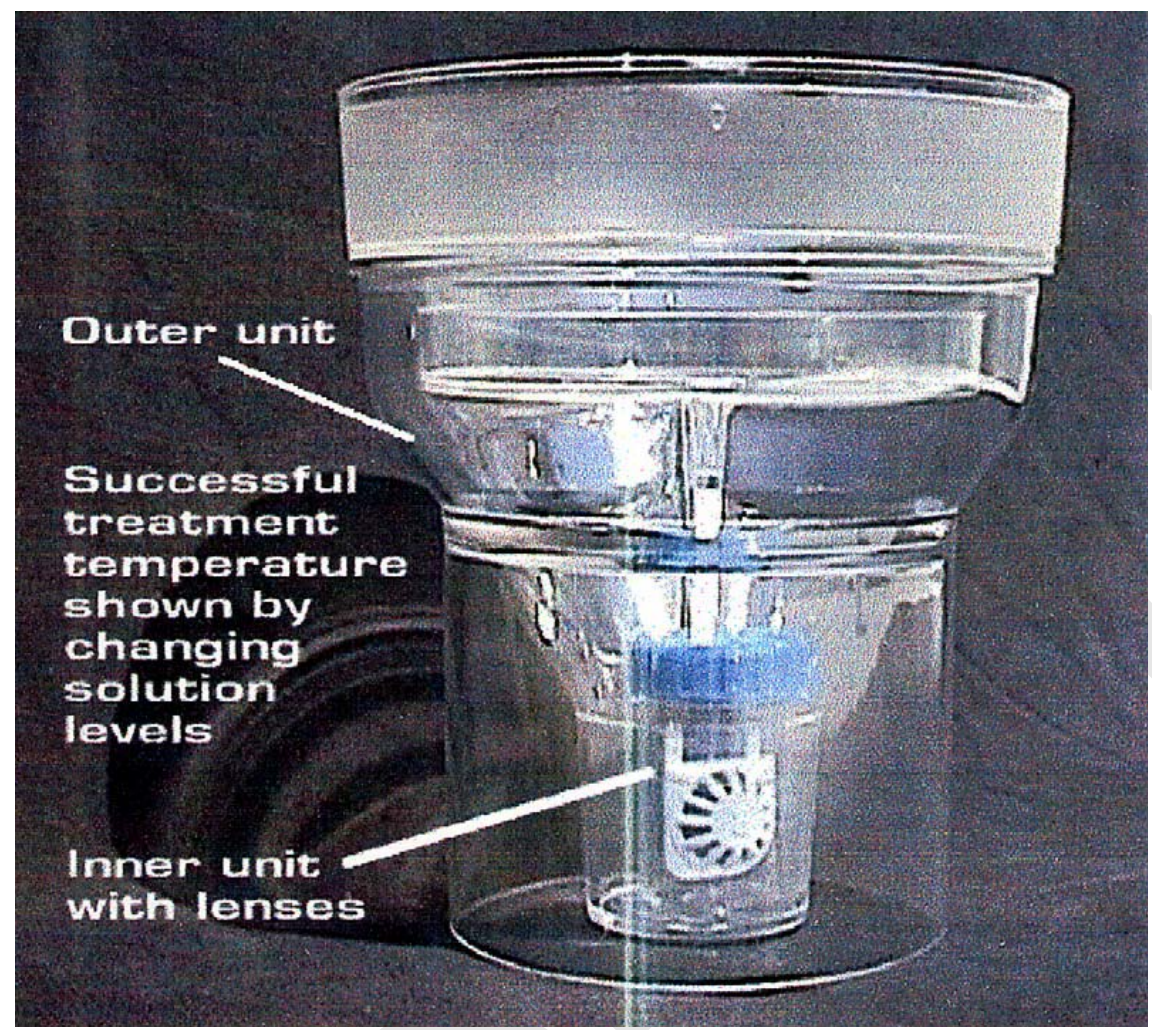

Figure 1 Original two part disinfector unit

The unit was a container designed to allow a standard form of storage case to be completely disinfected (elimination of all viable cells, but not spores) in a reproducible way that did not allow superheated solution droplets to escape the containers during irradiation and would give positive verification to the patient that the correct operating temperature had been achieved. The last task was essential to gain medical device accreditation and was achieved by allowing the storage case to back siphon solution from the outer container, in order to fill it with more solution than the patient had first introduced. This could only happen if the solution within the storage case had reached $100^{\circ} \mathrm{C}$, creating a partial vacuum inside the case when trapped steam condensed after irradiation

Simple as this approach sounds, it committed us to a gruelling EU medical device accreditation process lasting 2 years, in which we had to prove beyond reasonable doubt that the system was safe to advocate and market to patients, and did not damage the many different types of soft lenses they used. Such a process is intensive and very expensive. It required us 
to build and lead a project team with specialist expertise in microbiology, optometry, ophthalmology, pharmaceutics, product design, manufacturing and marketing. It required us to raise grants and later, venture funding to set up an aseptic production plant and quality systems for manufacture and distribution, which required further accreditation in the form of ISO 9000. Rather than rehearse here in detail the various challenges of this undertaking, I want to return to the other less obvious design responsibility issues that underlay our chosen path.

\section{Bio-massacre}

Our design problem and solution were largely pre-determined by the design of daily wear lenses. Consumer protection law required us to prove specific rates of kill for standard 'challenge' micro-organism. So just by choosing the design problem, we were committed to an environmental strategy of eradicating all microbial life from the lens storage area.

In this respect, ours was just one more of a growing number of products adopting this strategy to protect the consumer from the natural hazards of their personal environment. It is not only the consumer's foodstuffs and cosmetics that are defended by disinfecting treatments and preservatives, but entire rooms, such as kitchen and bathroom, for which there are ever more aggressive bactericidal cleaning agents.

Since microbial life is not sentient, it might appear rather ridiculous to question the responsibility of designing better ways of killing microbes. The relatively recent discovery of invisible microscopic species has not stirred the kind of human sentiments evident in the discovery of other species, such as deep marine life. The implication of microbial life in human disease seems to have focussed more of our creative energy on their containment, rather than their development, as might be better warranted in view of their essential contribution to our own elementary biological processes. (Although in the recent climate of environmental awareness, it is interesting to see how the publicity for foodstuffs like Yakut has played upon the imagery of 'friendly' bacteria.)

It does seem fair then to consider more carefully the potential side-effects generated by aggressive and indiscriminate disinfecting, a strategy which might be termed 'bio-massacre'. Even the general public is aware of the phenomenon of 'super bugs', micro-organisms that have developed resistance to common drug treatments. ${ }^{9}$ Some have argued that just as indiscriminate use of antibiotics promotes the development of resistant strains of micro-organisms, blanket use of disinfecting agents can do the same thing by creating competition-free environments conducive to the evolution of resistant mutant strains. ${ }^{10}$ Teams of microbiologists have even been able to demonstrate this phenomenon prospectively by developing in the laboratory, 
strains of common micro-organisms that were resistant to the widely used bactericide Triclosan. ${ }^{11}$ The press scares of 'super rats' (rats with an acquired immunity to the poison Warfarin) testifies that this mutation phenomenon also applies at the level of sentient life forms. ${ }^{12}$

Thus, there are purely strategic reasons for questioning the bio-massacre approach, and the choice of such an emotive label is intended to alert others to the potentially dangerous consequences. Some may say that there is no room for emotional advocacy in the sciences, but the present debates over the efficacy of bio-technological developments such as GM foods and cloning show this to be a wish, not a fact. Science is the product of emotional beings and operates within a cultural context. In this culture, commerce provides the necessary support to transform scientific concepts into technologies. In turn, commerce relies on marketing to cultivate consumer desire, and the publicising of 'germ threats' to consumers is a highly emotional market strategy for creating new product demand.

Science is also playing an active part in transforming our theological visions of the world in terms of adjusting our sense of universal scale and our recognition of just how special is the presence of life on our speck of a planet. Our understanding that the progenitors of this statistical miracle were the simple species our technology is attacking so indiscriminately seems bound to invoke non-scientific reasoning, particularly about our own role within the natural scheme. Speculation of this sort appears to reveal two rather different views of what may be called 'natural determinism'.

On the one hand, we may view nature as a wonderfully complex and finely tuned system, now under threat from our technological hubris, which unchecked, will doom many species, including our own, to a tragic fate. On the other, it may be argued that technology is simply a product of this system and the dire consequences for other species is only a matter of the natural system re-configuring itself to favour the most evolved and sophisticated of its species. Portrayed in theological terms, the first view could be characterised as a kind of mystery faith, akin to the animism of native Americans, the Buddhist sanctification of all life forms, or the divination of primal forces such as the Gaia system. ${ }^{13}$ The second view is anthropocentric, more akin to an Old Testament vision, where God, thehighest authority, has made this world in order to accommodate his greatest creation, to whom he has granted dominion over all its other creatures.

The mystery faith issues dark prophecies to advise technological caution (which are argued on both scientific as well as emotive grounds by organisations such as Greenpeace and Friends of the Earth). The anthropocentric faith promoted by corporations and their sponsored politicians evangelically promotes progress and growth (especially of markets). Like it or not, most designers are servants of the anthropocentric faith, which they may 
seek to re-direct from within, by espousal of 'environmentally friendly' strategies, but over which they have little real control, lacking the power and influence of a government that sets the agenda for consumer protection regulation and can choose to ignore initiatives to globalise environmental strategies.

The most powerful (and obdurate) of these governments includes among its constituents many of the world's leading developers of contact lens research and marketing. Few beneficiaries of their products may be inclined to renounce them on the basis of compassion for the microbial species which threaten to subvert product efficacy. Contact lens related diseases are painful and sight threatening. Yet, the literature shows that the risk of the most serious diseases is surprisingly low, being measured in fractions of a percent ${ }^{14,15}$ and can often be attributed to deficiencies of human nature, especially ignorance and laziness. ${ }^{16}$

Hence, any endeavour to design better lens wearing regimens pits the designer against both the natural world and human nature. Having committed ourselves to the bio-massacre strategy, we believed a major advantage of our system was that it made it much harder for the patient not to comply with the clinical necessity of disinfecting lenses, solution and all parts of the storage ease. ${ }^{17}$ In the event, the market reaction of our actual customers, optometrists, told us that our design was too inconvenient in requiring a change of care regimen from the bathroom to the kitchen. Furthermore, many optometrists were reluctant to take a product that in claiming $100 \%$ disinfection, invited unwelcome questions about the percentage kill achieved by their established products!

Late in the day, we did modify the design to one that used a multipurpose solution, and a much smaller lens case that gave patients the option to choose either a maximum effect 'hot' disinfecting treatment in the kitchen, or should that be inconvenient, a standard 'cold' treatment in another site (Figure 2). Unfortunately, the terms of our venture funding gave us insufficient time to make this adjustment, committing us to a single strike with our pilot design. 


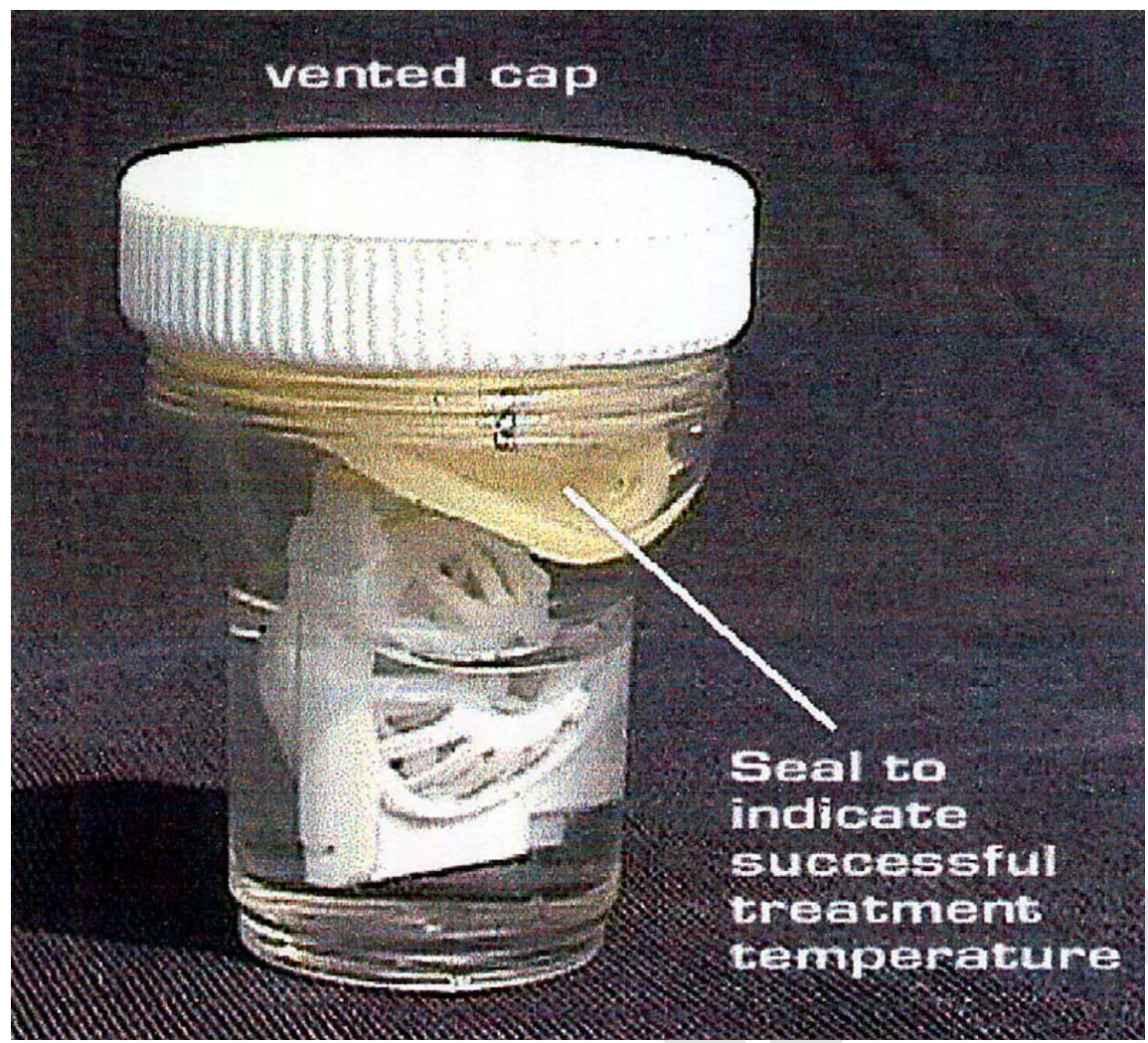

Figure 2 Mark II single part disinfector unit

\section{Mammon}

In private post mortems of our approach, a few leading clinicians raised doubts about the benefits of trying to improve the daily wear regimen. They saw such an endeavour as a stopgap measure while the industry as a whole was delivering the best design solution by developing daily disposable and extended wear lenses. In view of the design responsibility issues raised above this indeed seems a sensible view. Both systems effectively by-pass the need for bulky energy consuming care products that wage indiscriminate war on naturally occurring micro-organisms.

On the other hand, recent market figures suggest that the optimisation of the new designs is still some way off, since daily wear lenses continue to hold their ground and dominate market share. ${ }^{18}$ In this sense, the stopgap period is a remarkably long one, which at 6 years exceeds the expected life cycle for many other consumer products. Apart from the time it takes to move the dispensing profession from familiarity with one type of system to another, a key factor for the survival of daily lenses seems to be price. As long as daily disposables and extended wear lenses can command a premium price in respect of their novelty, and daily wear can cut costs to preserve their market share, the benefits of newer designs will be harder to pass on to patients. 
During this hiatus, the industry continues to hedge its bets by carrying on with new research and development in daily wear care products. The most notable recent development has been the 'hands off' chemical systems, such as Ciba Vision Focus Plus, which claim to obviate the need for the patient to rub and rinse the lens and storage case. These developments reinforce the sense of how design, research and development are merely aspects of a much more complex system of free-market technology, in which the designer's best solutions are not necessarily the most effective market ones.

The challenge then facing designers in the medical field is not simply a choice between two views of natural determinism, it also involves facing a third and perhaps more powerful 'theology' - that of Mammon. Even its most ardent devotees would probably accept that the relationship between retailer and consumer is not rational in the objective scientific sense. We discovered first hand that 'convenient' may be a better marketing pitch than 'safer', or that 'complete' disinfection is potentially a market threat, when a vague promise of a far less reliable 'disinfection' is already accepted by customers. The marketing campaign is waged as much for customer hearts as minds, and usually in deference to consumer ignorance and convenience.

These are factors which the designers of GM products do not seem to have fully grasped. They insist on drawing distinctions between scientific and other forms of argument, which they characterise as irrational or 'unscientific'19 (a discursive tactic eerily reminiscent of the charges of 'heresy' clerics levelled against Galileo's work). The opponents of GM appear to be less interested in the scientific rationale than the socio-political effects of introducing new subsistence crops which 'unnaturally' fail to produce seeds that can be planted to give the next year's crop. Opponents argue that this will give the handful of transnational corporations designing and developing these new strains an unfair and improper trading relationship with some of the world's poorest people. ${ }^{19}$ They also express concern about the provenance of the commercial sponsorship behind so many scientific reports favourable to GM design. The view that such arguments should not impinge on the 'science of' GM seems disingenuous and only heightens the feeling that the discourse of science is ill-equipped to reflect fully upon such matters.

\section{Conclusion}

More perceptive authors recognise that the very discourse of science is inextricable from earlier, often theological ones, and is but one of a number of discursive methods. ${ }^{20}$ If this is agreed, then the challenges of design responsibility are formidable indeed. Irrespective of their backgrounds in sciences or humanities, designers need to acquire understanding of more 
than one discourse to stand any chance of addressing the challenges of design responsibility.

This appears a daunting prospect in an age of increasing specialisation, as is clearly reflected in the current debates about the appropriate methodologies for design research. ${ }^{21,22}$ A notable feature of these debates is that they focus on such issues within the discipline of design. However, some exponents of this discipline have long argued that the activity of designing is not restricted merely to technological endeavour, and is essential to many day-to-day tasks. ${ }^{23}$ The issues of design responsibility and methodology are not peculiar to the design discipline. The trend to watch then, may be that of 'inter', 'trans', 'cross' or ' multidisciplinarity', evidenced in a number of new events such as the World Congress of Trandisciplinarity in Zurich in 2000 and journals such as Material Culture. The technological counterpart of these academic approaches is already evident in the project team approach used in commercial research and development, the very approach that enabled the case study here presented.

\section{References}

1 Russell, A D, Hugo, WB and Ayliffe, G A J Principles and practice of disinfection, preservation and sterilization, 2nd ed. Blackwell, Oxford (1992)

2 Weissman, B and Mondino, B J 'Why daily wear is still better than extended wear' Eye Contact Lens Vol 29 No 1 Suppl. (2003) S145-S146discussion S166, S192-S194

3 Cavanagh, H D, Ladage, P, Yemamoto, K, Li, S L, Petroll, W M, and Tester, J V 'Effects of daily and overnight wear of hyper-oxygen transmissible rigid and silicone hydrogel lenses on bacterial binding to the corneal epithelium: 13-month clinical trials’ Eye Contact Lens Vol 29 No 1 Suppl. S14-S16 discussion S26-S29, S192-S194,

4 Monopolies \& Mergers Commission 'Contact lens solutions: A report on the supply within the United Kingdom of contact lens solutions’ HMSO, Summary of Conclusions (1993) 207-208.

5 Lowe, R, Vallas, $\mathrm{V}$ and Brennan, $\mathrm{N}$ A 'Comparative efficacy of contact lens disinfection solutions’ CIAO Journal Vol 18 No 1 (1992) 34-40

6 Crabbe, $\mathrm{A}$ and Thompson, $\mathrm{P}$ 'Effects of microwave irradiation on the parameters of hydrogel contact lenses’ Optometry and Vision Science Vol 78 No 8 (2001) 605-609

7 Herbst, R A and Maibach, H I 'Contact dermatitis caused by allergy to ophthalmic drugs and contact lens solutions’ Contact Dermatitis Vol 25 No 5 (1991) 305-312

8 Kilvington, S 'Acanthamoeba trophozoite and cyst adherence to four types of soft contact lens and removal by cleaning agents’ Eye Vol 7 No Pt 4 (1993) 535- 538

9 The Guardian (London) Scottish microbes may take on superbugs, 27th February 2003.

10 Levy, S B ‘Antibacterial household products: cause for concern’ Emerging Infectious Diseases Vol 7 No 3 Suppl. (2001)

11 McMurry, L M, Oethinger, M and Levy, S B ‘Triclosan targets lipid synthesis’ Nature Vol 394 (1998) 531-532

12 Daily Telegraph (London) Super rats pose threat to Britain, 9th November 2000. 
13 Lovelock, J Gaia: a new look at the earth Oxford University Press, Oxford (1979)

14 Nilsson, S E and Montan, P G'The annualised incidence of contact lens induced keratitis in Sweden and its relation to lens type and wear schedule: results of a 3 month prospective study' CLAO Journal Vol 20 No 4 (1994) 225-230

15 Radford, C F, Minassian, D C and Dart, J K 'Acanthamoeba keratitis in England and Wales: incidence, outcome, and risk factors’ British Journal of Ophthalmology Vol 86 No 5 (2002) 536542

16 Claydon, B E and Efron, N 'Non compliance in contact lens wear' Ophthalmic and Physiological Optics Vol 14 Oct (1994) 356-364

17 Crabbe, A and Thompson, $\mathrm{P}$ 'Clinical trial of a patient operated microwave disinfection system for hydrogel contact lenses’ Optometry and Vision Science Vol 78 No 8 (2001) 610-615 18 Association of Contact Lens Manufacturers, Market Trends 2002 (internal document).

19 Tudge, C, Leaver, C and Trewavas, A ‘Brave new world?’ New Scientist Vol 178 No 2389 (2003) 44-47

20 Klee, $\mathrm{R}$ in Introduction to the philosophy of science: cutting nature at its seams, Oxford University Press, Oxford (1997) pp 104-124

21 Cross, N ‘Design research: a disciplined conversation’ Design Issues Vol 15 No 2 (1999) 5-10

22 Margolin, V ‘Design research and its challenges’ Design Journal Vol 4 No 2 (1999) 14-19

23 Papanek, V in Design for the real world: human ecology and social change, 2nd ed., Thames and Hudson, London (1985) pp 3-27 